\title{
Incidence of Thyroid Disorders in India: An Institutional Retrospective Analysis
}

\author{
Rajnish Nagarkar, Shirsendu Roy, Mohammad Akheel, Vijay Palwe, Nayana Kulkarni, \\ Prakash Pandit
}

\author{
Department of Oncology, Curie Manavata Cancer Centre, Nashik, Maharashtra, India
}

\begin{abstract}
Aim: Thyroid disorders are common endocrine disorders encountered in the African continent. Environmental and nutritional factors are often implicated in the occurrence of most thyroid disorders that occur in the most part of the world. This is a narrative review that seeks to document the pattern, prevalence, and management of thyroid disorders in the continent. To find the incidence and prevalence of thyroid disorders from total body malignancies at our cancer center. Objective: Implementation of thyroid screening camps among the general population. In India, thyroid disorders in childhood and adolescence have not been sufficiently studied. Where studies are available, they were either conducted decades ago or they involved only adults. The objectives of this study are to describe the pattern of thyroid disorders in each individual seen in our hospital and to highlight the management challenges encountered. Materials and Methods: This is a retrospective medical record analysis performed in our tertiary care cancer center in Nasik, Maharashtra for a period of 6 years from January 2008 to December 2014. The clinical examination, biochemical studies, serological and histological parameters were used to characterize and evaluate the patients of thyroid disorders. Investigations done, surgical treatment type, types and complications of thyroid disorders, incidence according to age, sex and prognosis were all documented in this analysis. Results: Of 16933 cancer patients, 128 patients suffered from thyroid disorders and the prevalence was $0.8 \%$. The prevalence of thyroid disorders was significantly higher in females than males $\left(33.6 \%\right.$ vs. $\left.66.4 \%, \chi^{2}=27.56, P<0.001\right)$. The prevalence of thyroid disorders was significantly higher in higher aged ( $\geq 31$ years) patients as compared to lower aged ( $\leq 30$ years) patients $\left(14.1 \%\right.$ vs. $\left.85.9 \%, \chi^{2}=132.30, P<0.001\right)$. Of total thyroid disorders, 99 (77.3\%) patients had cancers with highest prevalence of follicular cancer (58.6\%). Of total thyroid disorders, $79(61.7 \%)$ patients underwent surgery with no postoperative complications and were discharged on $3^{\text {rd }}$ day of surgery. The mortality rate was $4.6 \%$. Conclusion: There are a high risk and burden of thyroid disorders in India due to lack of nutrition and unavailability of proper therapeutic resources. There are a lack and paucity of data on the epidemiology of thyroid disorders. Due to lack of resources, complete screening for thyroid diseases in the general population is not cost-effective. There must be complete family screening with all genetic relatives in all patients with juvenile autoimmune thyroiditis.
\end{abstract}

Key words: Management, thyroid disorders, thyroidectomy

\section{INTRODUCTION}

Thyroid diseases are now a day's very common in India and has brought focus on this by a wide

\begin{tabular}{|c|c|}
\hline \multicolumn{2}{|c|}{ Access this article online } \\
\hline Publisher & \multirow[b]{2}{*}{$\begin{array}{l}\text { Website: } \\
\text { www.renupublishers.com }\end{array}$} \\
\hline & \\
\hline & $\begin{array}{l}\text { DOI: } \\
\text { 10.5958/2394-4196.2015.00012.6 }\end{array}$ \\
\hline
\end{tabular}

range of surgeons and doctors. With the widespread availability of thyroid function testing in recent years increasing numbers of patients with symptoms, which might be attributable to hypothyroidism and hyperthyroidism are being tested. Many aspects of the management of thyroid disorder have not yet been subjected to controlled clinical trials yet there are established practices, which have never been questioned. The Research Unit of the Royal College of Physicians of London, the Endocrinology and Diabetes Committee of the college, and the Society for Endocrinology set up a working group to

\section{Address for Correspondence:}

Dr. Mohammad Akheel, Curie Manavata cancer centre, Opposite to Mahamarg Bustand, Nashik, Maharashtra, India. Phone: +91-7058401419. Email-drakheelomfs@gmail.com

Submission: 22 Feb 2015; Revision: 10 Mar 2015; Re-Revision: 21 Apr 2015; Acceptance: 09 May 2015 
produce a consensus statement for good practice with associated audit measures, which could be used to ensure that purchasers of health care are obtaining an acceptable standard of care for patients with thyroid disease. The working group focused on patient management rather than presenting symptoms and signs, which were detailed in a similar report by the American Thyroid Association.

Endocrine disorders are common among Indian population out of which thyroid disorders represents an important subset of these endocrine disorders. ${ }^{[1]}$ According to western literature around $50 \%$ of people in the community have microscopic nodules, $5 \%$ of women have overt hypothyroidism or hyperthyroidism, $15 \%$ have palpable goiters, $3.5 \%$ have occult papillary carcinoma and $10 \%$ demonstrate an abnormal thyroid-stimulating hormone level. ${ }^{[2-4]}$ Among all these, thyroid cancer is the most common endocrine malignancy with more mortality when compared to all other endocrine cancers. ${ }^{[5]}$ The burden of thyroid disorders in the general population is enormous. The prevalence of these thyroid disorders varies widely according to geographical distribution, diet and nutrition and patient population. According to the literature, autopsy rates ranging from $0.03 \%$ to over $2 \%$ have been reported. ${ }^{[6]}$ Mortensen et al. reported a $2.8 \%$ prevalence rate and also account $4 \%$ of patients with metastatic neoplasm with secondary tumors to the thyroid gland and on 1000 consecutive patients of thyroid carcinoma in routine autopsies. ${ }^{[7]}$

\section{MATERIALS AND METHODS}

A retrospective study was performed in a specialized cancer center "Curie Manavata Cancer Centre," Nasik, in Northern Maharashtra during a 6 year period from January 2008 to December 2014. The cancer center has a special setup starting from surgical oncology, medical oncology and radiation oncology. The institute also has PET scan installed with Lineac accelerator. Of 16933 cancer patients, 128 patients suffered from thyroid disorders.

\section{Statistical Analysis}

The discrete (categorical) data were summarised as no and $\%$ and compared by Chi-square $\left(\chi^{2}\right)$ test. A two-tailed $P<0.05$ was considered statistically significant.

\section{RESULTS}

Out of 16933 malignancies, 128 patients suffered from thyroid disorders and thus the prevalence of thyroid disorders was $0.8 \%$ [Figure 1].

The distribution of thyroid disorders according to sex is shown graphically in Figure 2. Among thyroid disorders, $43(33.6 \%)$ were males and 85 (66.4\%) were females and the prevalence of disorders was significantly higher in females than females $\left(33.6 \%\right.$ vs. $66.4 \%, \chi^{2}=27.56$, $P<0.001)$.

The distribution of thyroid disorders according to age is depicted in Figure 3. Of total thyroid disorders, $18(14.1 \%)$ patients were between 10 and 30 years,

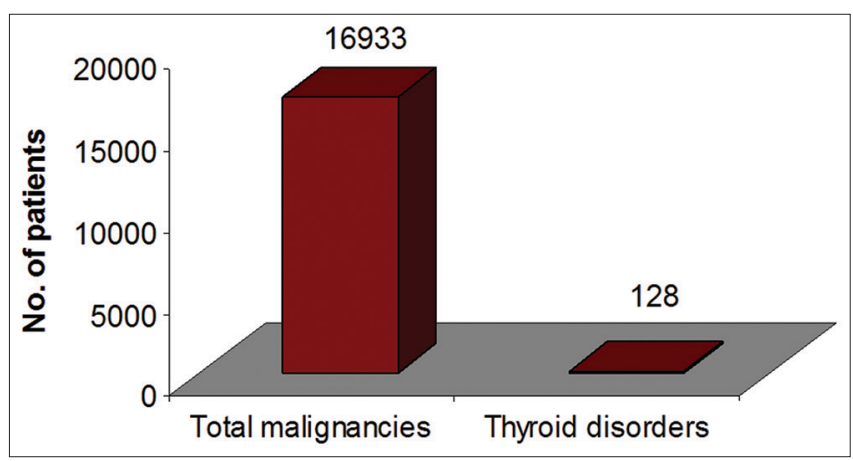

Figure 1: Incidence of thyroid disorders

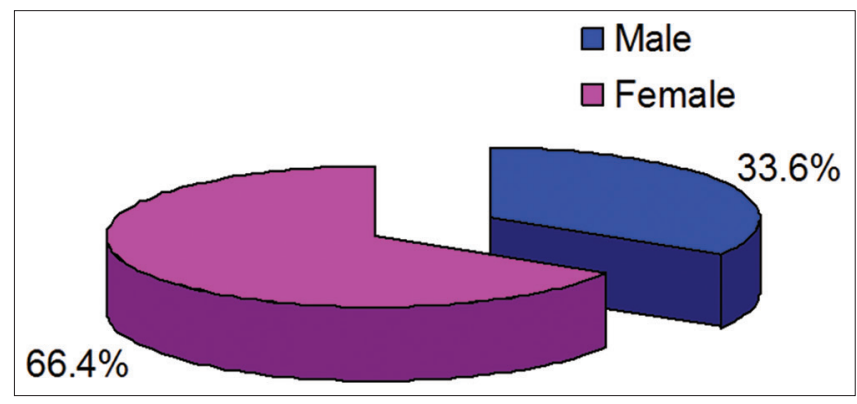

Figure 2: Incidence of thyroid disorders according to sex

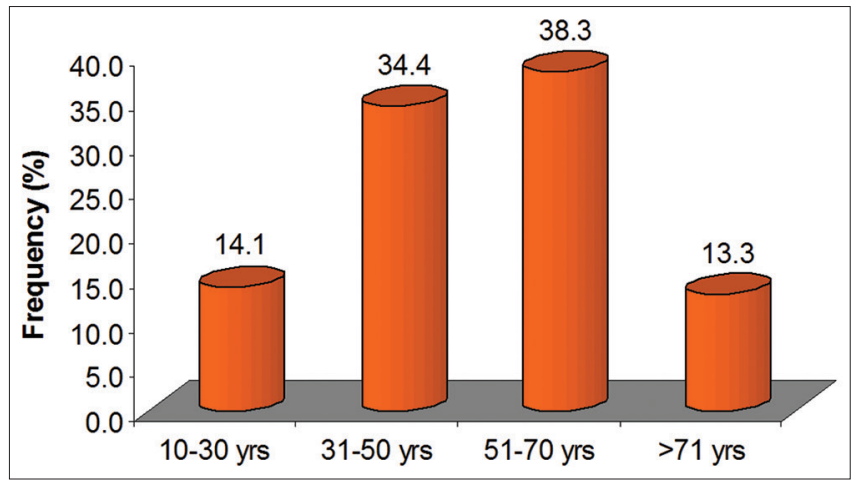

Figure 3: Incidence of thyroid disorders according to age 
$44(34.4 \%)$ patients were $31-50$ years, 49 (38.3\%) patients were $51-70$ years and $17(13.3 \%)$ patients were above 71 years. The prevalence of thyroid disorders was significantly higher in higher aged ( $\geq 31$ years) patients as compared to lower aged ( $\leq 30$ years) patients (14.1\% vs. $\left.85.9 \%, \chi^{2}=132.30, P<0.001\right)$.

The distribution of thyroid disorders is summarized in Table 1. Of total malignancies, thyroid cancers was in 99 patients accounting $77.3 \%$ of total malignancies with highest being of follicular cancers (58.6\%), followed by papillary type $(35.4 \%)$, medullary type (4.0\%) and anaplastic type (2.0\%). Further, 10 (7.8\%) of patients showed regional metastasis, 11 (8.6\%) patients had solitary nodules and $4(3.1 \%)$ patients have autoimmune Hashimotos thyroiditis.

Of total 128 thyroid disorders patients, 79 (61.7\%) patients were operated of which $36(45.6 \%)$ patients underwent hemithyroidectomy, 28 (35.4\%) patients underwent total thyoridectomy, 11 (13.9\%) patients underwent subtotal thyroidectomy and 4 (5.1\%) patients underwent complete thyroidectomy. Further, $27(21.1 \%)$ patients underwent neck dissection. All patients were discharged on $3^{\text {rd }}$ after surgery. The mortality rate was $4.7 \%$.

\section{DISCUSSION}

Tumors of thyorid gland are the most common endocrine neoplasms found in India out of which 5-10\% of all thyroid nodules are carcinomas. ${ }^{[8]}$ Diagnosis of any thyroid tumor can be made by thorough medical history, clinical examination, Biopsy and radiographic imaging. Histopathological examination can be made by Fine needle aspiration cytology (FNAC). ${ }^{[9]}$ The prognosis for thyroid carcinoma is worse in endemic goiter regions, in comparison with regions with an adequate dietary iodine intake. There is a higher incidence of un-differentiated thyroid malignancies in iodine deficiency areas. ${ }^{[10]}$ Sometimes, in iodine deficiency papillary neoplasms predominate over follicular cancers. While in our study follicular carcinoma represented for $58.5 \%$ of thyroid cancers while papillary cancers for $35.3 \%$. There was a major study done in United States comparing goiter prevalence and the effect of iodine supplementation with thyroid cancer, which failed to support a link between endemic goiter and thyroid cancer. ${ }^{[11,12]}$ Few studies also state that there is always an increased risk of thyroid carcinomas, including Graves's diseases. However, the data remains still inconclusive, and the reported cancer rates range from $0.06 \%$ to as high as 8.7\%. ${ }^{[13]}$ Dijkstra et al. ${ }^{[14]}$ Retrospectively reviewed data from 1970 to 1996 and observed a significant increase in papillary thyroid carcinomas in parallel with increases in iodine intake. Indeed, a higher incidence of thyroid cancer has been noted in regions enjoying introduction of iodine prophylaxis against goiter and a predominance of papillary over follicular thyroid cancer in areas of iodine surfeit is well recognized, as is the association, on the other hand, of iodine deficiency with follicular carcinomas. ${ }^{[15,16]}$

The incidence of thyroid cancers increases with age. In our study, out of 128 patients, 49 patients affected were from the age group of 51-70 years and 17 patients affected were above 71 years. Thyroid cancer is more common in females than males. ${ }^{[17]}$ The female predominance suggests that hormonal factors may be involved. In our study, male to female incidence was 1:1.9. The literature also says that there can be biological changes occurring during pregnancy may increase the risk of thyroid carcinoma. Some genetic syndrome like Gardner syndrome, adenomatous polyposis coli, and Cowden's disease are associated with an increased risk of thyroid cancer. ${ }^{[18]}$ There is also evidence that indicates individuals with Hashimoto's thyroiditis have an increased risk to develop thyroid lymphomas. ${ }^{[19]}$

The thryoid gland is usually very sensitive to both external and internal radiation. Radio-iodine is employed therapeutically for diffuse and nodular toxic goiter and thyroid cancer. This gland is arguably the only endocrine organ with a documented major rise in the incidence of cancers after radiation exposure, especially in children. External radiation therapy for a variety of benign conditions of the head and neck was introduced between 1920 and 1950. There is a linear relationship between radiation doses up to 1800 rads and the incidence of thyroid nodules and cancer. ${ }^{[20]}$ The increase in the risk of clinically significant thyroid cancer associated with prior radiotherapy to the head and neck given for thymic enlargement, tonsillitis, acne, and adenitis is around $3 \%$.

Robust diagnostic facilities for thyroid disorders are lacking in most countries in Africa and the commonly employed diagnostic techniques include immunoassays, serology, ultrasonography cytology, and histopathological techniques for the evaluation of thyroid nodules. ${ }^{[21]}$ In children and adolescents, the range of iodine deficiency disorders (IDD) 
Table 1: Type of thyroid disorders

\begin{tabular}{lc}
\hline Thyroid disorders & Number of patients $(\boldsymbol{n = 1 2 8 )} \mathbf{( \% )}$ \\
\hline Hypothyroidism (primary) & $2(1.6)$ \\
Hyperthyroidism (primary) & $1(0.8)$ \\
Thyroglossal cyst & $1(0.8)$ \\
Ca thyroid & $99(77.3)$ \\
Ca thyroid with metastasis & $10(7.8)$ \\
Solitary nodule & $11(8.6)$ \\
Hashimotos thyroiditis & $4(3.1)$ \\
\hline
\end{tabular}

include goiter, subclinical hypothyroidism, impaired mental function, retarded physical development, and increased susceptibility of the thyroid gland to nuclear radiation. In adults, IDD includes goiter with its complications, hypothyroidism, impaired mental function, spontaneous hyperthyroidism in the elderly, iodine-induced hyperthyroidism, and increased susceptibility of the thyroid gland to nuclear radiation. Computed tomographic scans and magnetic resonance imaging facilities are also not widely available, but when available are often inaccessible for most patients because of the system of health care provision which is often that of "out of pocket" payment. ${ }^{[22]}$

Finally, if technically feasible, thyroidectomy can be effective for local control. ${ }^{[23,24]}$ Surgical resection is regarded as the best treatment for a metastatic thyroid tumor, especially if the primary carcinoma appears to be controlled and there is no evidence of metastasis elsewhere. ${ }^{[25]}$

The incidence of regional metastasis was very minimal with very les mortality. In our study out of 128 patients 79 patients were operated and remain free of disease for follow-up of 5 years. 36 patients underwent hemithyroidectomy, 28 patients underwent total thyroidectomy, 11 patients underwent subtotal thyroidectomy and 4 patients underwent complete thyroidectomy and $27(21 \%)$ patients underwent neck dissection. Out of 128 patients the mortality rate was $4.6 \%$.

A South Africa study ${ }^{[26]}$ recorded a high incidence of new onset thyroid dysfunction (TD) in a subset of 163 patients after a median duration of 369 days of treatment with amiodarone for cardiac arrhythmias. The percentage of the patients that developed new onset TD was $27.6 \%$ of which subclinical hypothyroidism and subclinical hyperthyroidism were the commonly documented for TD.
This retrospective analysis suggests that for early identification of the thyroid disorders or nodules screening and thyroid hormones level should be done for all age groups of general population. There must be congenital hypothyroidism screening for all newborns and establishment of a national screening program. FNAC remains the gold standard for histopathological diagnosis. Implementing these preventive measures would go a long way in improving and management of the thyroid health of our population.

FNAC can allow for the preoperative diagnosis of a secondary tumor, thus changing the preoperative work-up of such patient. ${ }^{[27,28]}$ Once the diagnosis of the metastatic disease has been confirmed on FNA, the patient should undergo a metastatic work-up to rule out other distant metastases. ${ }^{[28,29]}$

\section{CONCLUSION}

Diagnosis and management of thyroid disorders in the Asian and African continent remain suboptimal. Thyroid disorder registries may be helpful to determine the scope of the burden of thyroid disorders since this knowledge may help change policies on the approach to the management of these disorders. Iodine nutrition should be ensured in all women of reproductive age group. There must be family screening for immediate relatives in all patients with juvenile autoimmune thyroiditis. The above suggestions are based on evidence from Indian and Western literature and clinical guidelines of various organizations. The study recommends time to time thyroid screening camps along with the challenges facing poor accessibility to diagnostic and therapeutic facilities. It is imperative that thyroid management guidelines should be taking into consideration by our resources available even in poor background set up and awareness programs should also be done to prevent thyroid disorders in general population all over the world.

\section{REFERENCES}

1. Vanderpump MP, Tunbridge WM, French JM, Appleton D, Bates D, Clark F, et al. The incidence of thyroid disorders in the community: A twenty-year follow-up of the whickham survey. Clin Endocrinol 1995;43:55-68.

2. Aghini-Lombardi F, Antonangeli L, Martino E, Vitti P, Maccherini D, Leoli F, et al. The spectrum of thyroid disorders in an iodine-deficient community: The Pescopagano survey. J Clin Endocrinol Metab 1999;84:561-6.

3. Peter L, Pedersen KM, Hreidarsson A, Sigfusson N, Iversen E, Knudsen PR, et al. Iodine intake and the pattern of thyroid disorders: A comparative epidemiological study of thyroid abnormalities in the elderly in Iceland and in Jutland, Denmark. J Clin Endocrinol Metab 1998;83:765-9. 
4. Vanderpump MP. The epidemiology of thyroid disease. Br Med Bull 2011;99:39-51.

5. Gopalakrishnan UA, Menon UV. Thyroid disorders in India: An epidemiological perspective. Indian J Endocrinol Metab 2001;15:S78.

6. Louise D, Welch HG. Increasing incidence of thyroid cancer in the United States, 1973-2002. JAMA 2006;295:2164-7.

7. Mortensen J, Woolner LB, Bennett WA. Secondary malignant tumors of the thyroid gland. Cancer 1956;9:306-9.

8. Gharib H. Current evaluation of thyroid nodules. Trends Endocrinol Metab 1994;5:365-9.

9. Shore RE. Issues and epidemiological evidence regarding radiationinduced thyroid cancer. Radiat Res 1992;131:98-111.

10. David S, Fraumeni Jr JF. Cancer Epidemiology and Prevention. Eastbourne, UK; WB Saunders Co.; 1982.

11. Sipos JA, Mazzaferri EL. Thyroid cancer epidemiology and prognostic variables. Clin Oncol 2010;22:395-404.

12. Laurence L, Grosclaude P, Chérié-Challine L. Increased incidence of thyroid carcinoma in France: A true epidemic or thyroid nodule management effects? Report from the French Thyroid Cancer Committee. Thyroid 2004;14:1056-60.

13. John VB, Gaston EA, Dawber TR. The significance of nontoxic thyroid nodules: Final report of a 15-year study of the incidence of thyroid malignancy. Ann Intern Med 1968;69:537-40.

14. Ron E, Lubin JH, Shore RE, Mabuchi K, Modan B, Pottern LM, et al. Thyroid cancer after exposure to external radiation: A pooled analysis of seven studies. Radiat Res 1995;141:259-77.

15. Dijkstra G, de Rooij DG, de Jong FH, van den Hurk R. Effect of hypothyroidism on ovarian follicular development, granulosa cell proliferation and peripheral hormone levels in the prepubertal rat. Eur J Endocrinol 1996;134:649-54.

16. Amy CY, Jemal A, Ward EM. Increasing incidence of differentiated thyroid cancer in the United States, 1988-2005. Cancer 2009;115:3801-7.

17. Tucker MA, Jones PH, Boice JD Jr, Robison LL, Stone BJ, Stovall M, et al. Therapeutic radiation at a young age is linked to secondary thyroid cancer. Cancer Res 1991;51:2885-8.

18. Clark $\mathrm{OH}$. Total thyroidectomy: The treatment of choice for patients with differentiated thyroid cancer. Ann Surg 1982;196:361-70.

19. Mazzaferri EL. Managing small thyroid cancers. JAMA 2006;295:2179-82.

20. Hardy KJ, Walker BR, Lindsay RS, Kennedy RL, Seckl JR, Padfield PL. Thyroid cancer management. Clin Endocrinol (Oxf) 1995;42:651-5.

21. David CS, Doherty GM, Haugen BR, Kloos RT, Lee SL, Mandel SJ, et al. Revised American Thyroid Association management guidelines for patients with thyroid nodules and differentiated thyroid cancer: The American thyroid association (ATA) guidelines taskforce on thyroid nodules and differentiated thyroid cancer. Thyroid 2009;19:1167-214.

22. Green LK, Ro JY, Mackay B, Ayala AG, Luna MA. Renal cell carcinoma metastatic to the thyroid. Cancer 1989;63:1810-5.

23. Saitoh H. Distant metastasis of renal adenocarcinoma. Cancer 1981;48:1487-91.

24. Ogbera AO, Kuku SF. Epidemiology of thyroid diseases in Africa. Indian J Endocr Metab 2011;15:82-8.

25. Tubiana M, Haddad E, Schlumberger M, Hill C, Rougier P, Sarrazin D. External radiotherapy in thyroid cancers. Cancer 1985;55:2062-71.

26. Post FA, Soule SG, Willcox PA, Levitt NS. The spectrum of endocrine dysfunction in active pulmonary tuberculosis. Clin Endocrinol (Oxf) 1994;40:367-71.

27. Heffess CS, Wenig BM, Thompson LD. Metastatic renal cell carcinoma to the thyroid gland: A clinicopathologic study of 36 cases. Cancer 2002;95:1869-78.

28. Friberg S Jr, Kinnman J. Renal adenocarcinoma with metastases to the thyroid gland. Acta Otolaryngol 1969;67:552-62.

29. Gault EW, Leung TH, Thomas DP. Clear cell renal carcinoma masquerading as thyroid enlargement. J Pathol 1974;113:21-5.

How to cite this article: Nagarkar R, Roy S, Akheel M, Palwe V, Kulkarni N, Pandit P. Incidence of Thyroid Disorders in India: An Institutional Retrospective Analysis. Int J Dent Med Spec 2015;2(2):19-23.

Source of Support: Nil; Conflict of Interest: None 